\title{
Deprem Bölgesi Haritasından Kontur İçeren Deprem Tehlike Haritasına Geçişin Çeşitli Yapılarda Tasarım ve Analiz Deprem Yükü Taleplerine Etkisi
}

\author{
Hümeyra ŞAHİN ${ }^{1}$, Ayşe Ruşen DURUCAN ${ }^{2}$, Cengizhan DURUCAN ${ }^{3}$, \\ 1 İnşaat Mühendisliği Bölümü, Mühendislik Fakültesi, Fırat Üniversitesi, Elazı̆̆g, Türkiye \\ 2 İnşaat Mühendisliği Bölümü, Mühendislik Fakültesi, Fırat Üniversitesi, Elazığ, Türkiye \\ ${ }^{3}$ İnşaat Mühendisliği Bölümü, Teknoloji Fakültesi, Fırat Üniversitesi, Elazığ, Türkiye \\ ${ }^{* 1}$ hsahin@ firat.edu.tr, ${ }^{2}$ ardurucan@ firat.edu.tr, cdurucan@ firat.edu.tr
}

\begin{abstract}
Öz: Bu araştırma, deprem bölgesi harita konseptinden (TDY-2007) kontur içerikli deprem tehlike haritasına (TDY-2019) geçiş nedeniyle oluşan değişikliğin yapılar üzerindeki etkilerini değerlendirmeyi amaçlamaktadır. Çalışmada, ilk olarak Türkiye'nin depremslliği yüksek olan bir bölgesinden seçilen örnek noktaların koordinat bazlı elastik ve azaltılmış tasarım ivme spektrumları elde edilmiştir. Elastik tasarım ivme spektrumlarının karşılaştırmalı analizleri için 4 zemin sınıfı ve 3 performans seviyesi ana parametre olarak kabul edilmiştir. Azaltılmış tasarım ivme spektrumlarının karşılaştırılması için; (i) 4 zemin sınıfı, (ii) 3 performans seviyesi, (iii) 4 bina tipi ve (iv) 2 taşıyıcı sistem tipi ana parametre olarak seçilmiştir. Daha sonra yeni deprem yönetmeliğinden elde edilen bu spektrumlar, Türkiye'deki yapıların tasarımı için kullanılan önceki deprem yönetmeliğinin tasarım ivme spektrumları ile karşılaştııılmıştır. Tasarım ivme spektrumu, (i) spektral elastik değerler ve (ii) azaltılmış tasarım spektral ivme değerleri açısından karşılaştırılmıştır. Karşılaştırmalı sonuçlar, temel olarak kısa periyot bölgesinde, güncel tasarım yaklaşımından elde edilen spektral ivme değerlerinin, önceki tasarım yaklaşımı kullanılarak elde edilen spektrumlardan önemli ölçüde daha yüksek olduğunu göstermiştir. Bununla birlikte, daha uzun periyot aralığ için, eski tasarım spektrumu kullanarak elde edilen spektral değerler, yeni tasarım spektrumları hesaplama prosedürü kullanılarak hesaplananlardan daha büyüktür.
\end{abstract}

Anahtar Kelimeler: Elastik tasarım ivme spektrumu, azaltılmış tasarım ivme spektrumu, TDY-2019, Doğu Anadolu fay zonu.

\section{Transition from Seismic Zonation to Seismic Hazard Contour Map and Its Effects on the Variation of Earthquake Design and Analysis Load Demands for Various Type of Structures}

\begin{abstract}
This research study is aimed at evaluating the effects of the variations in the level of earthquake demands on the structures due to the transition from earthquake zone map concept (TEC-2007) to the seismic contour hazard map (TEC2019). In the study, coordinate based elastic and reduced design acceleration spectrum of sample points selected for one of the high seismicity regions of Turkey are obtained. For the comparative analyses of elastic design acceleration spectrum, 4 site classes and 3 performance levels are considered as main parameters. For the comparison of reduced response spectrum, (i) 4 site classes, (ii) 3 performance levels, (iii) 4 building types and (iv) 2 structural framing systems were selected as main parameters. Then, these spectrums are compared with the design acceleration spectrum of preceding design approach used for the design and analyses of the structures in Turkey. The design acceleration spectrum is compared in terms of (i) spectral elastic values and (ii) design spectral accelerations. The comparative results mainly showed that in the short period range the spectral acceleration values obtained from the up to date design approach are significantly higher than their counterparts obtained by using the preceding design approach. However, for the longer period range the spectral values obtained using the old response spectrum were higher than those calculated using the new response spectra calculation procedure.
\end{abstract}

Keywords: elastic design acceleration spectra, reduced design acceleration spectra, TEC-2019, East Anatolian fault zone,

\section{Giriş}

Depremlerden kaynaklanan sosyal ve ekonomik kayıplar, genellikle tehlike bölgesindeki günlük yaşamı da uzun süre olumsuz yönde etkiler. Bir bölgenin depremselliğini değiştirmek mümkün olmadı̆̆ 1 için yer hareketlerinin yıkıcı etkisini azaltmanın tek yolu, beklenen deprem yüklerine karşı koyabilecek yapılar inşa etmektir. Bu tip yapılar inşa etmek yapılar üzerinde beklenen deprem yüklerinin yüksek isabetle tahmin edilmesini gerektirmektedir. Beklenen deprem yüklemesi ise genellikle hesaba bağlı olarak tahmin edilen yer hareketi parametreleri ile karakterize edilen bir tasarım yer hareketi kullanılarak tanımlanır [1]. Bu

\footnotetext{
* Sorumlu yazar: ardurucan@firat.edu.tr. Yazarların ORCID Numaras: ${ }^{1}$ 0000-0001-9563-8450, ${ }^{2}$ 0000-0002-3271-2438, ${ }^{3} 0000-0002-1933-$ 8218
} 
parametrelerin tahmini için geçmişten günümüze gelişerek gelen yöntemler kullanılmaktadır. Deprem mühendisliği ve sismoloji alanında yığılarak artan bilgiler, yeni bulgular, geliştirilen hassas cihazlar ile yeni yöntemler olası deprem yüklerinin tahmini için kullanılan tekniklerin gelişmesine yol açmaktadır. Yukarıda oldukça kısa şekilde açıklanmaya çalışılan deprem yükü talebinin tahmini ile ilgili perspektifin yanı sıra bir de tasarım kriterleri ile ilgili gelişmeler söz konusudur. Örneğin, performansa dayalı tasarım ve analiz yöntemleri son on yıllarda popülerlik kazanmış ve birçok yeni tasarım kriterine yol açmıştır. İki yönlü (talep deprem yükü ve yapı davranışı ile ilgili kriterler) ilerleyen bu gelişimsel sürece bağlı olarak ülkeler, yapısal tasarım şartnamelerini sürekli yenilemektedir.

Deprem tasarım yüklerinin hesaplanmasında 1990'lı yılların sonlarına kadar deprem bölgeleri yaklaşımının dünya genelinde yaygın olarak kullanıldığı bilinmektedir [2]. Son zamanlarda bu yaklaşımın aksayan bazı yönlerinin olduğu görülmektedir. Bu yönlerden bir tanesi ise gerçekte fay bölgesinden uzaklığa göre değişim gösteren sismik tasarım parametrelerinin bu yaklaşımda bir bölge boyunca sabit olduğunun kabul ediliyor olması durumudur. Bu yaklaşım bazen güvenlik bazen de ekonomik açıdan olumsuz sonuçlara yol açabilmektedir. Bu gibi eksik yönleri gidererek daha isabetli deprem tasarım yükleri elde edebilmek için deprem tasarım parametrelerinin, sahanın faya olan konumuna göre sürekli değişimini yansitabilen kontur içeren deprem tehlike haritaları geliștirilmiştir.

Deprem yüklerinin tahmin edilmesi için deprem bölgeleri haritasından, kontur içeren deprem tehlike haritası konseptine yakın zamanda geçmiş olan Türkiye ise bu konuda güncel bir örnek oluşturmaktadır. Bu çalışmada deprem bölgesi haritasından, kontur içeren deprem tehlike haritasına geçişin yapılar üzerindeki etkileri araştırılacaktır. Ancak öncelikle Türkiye'de depreme karşı dayanıklı yapı tasarımı için kullanılan yöntemlerin ve deprem tehlike haritalarının değişimi hakkında kısaca bilgi verilecektir.

Yapılara gelen deprem yüklerinin belirlenmesinde, tasarım ivme spektrumu yaklaşımı kullanılmaktadır. Bu yaklaşım ilk defa Türk Deprem Yönetmeliği (TDY-1998) [3] ile kullanılmaya başlanmış, TDY-2007'de [4] ise değişiklik yapılmadan aynı tasarım yaklaşımı benimsenmiştir. Ancak, 2018 yılında deprem yönetmeliği ve deprem tehlike haritası ile ilgili yapılan çalışmalar neticesinde tasarım ivme spektrumu hesaplarında kapsamlı değişiklikler yapılmış ve bu değişiklikler TDY-2019 [5] ile yürürlüğe girmiştir.

Türkiye'de resmi olarak kullanılan ilk deprem tehlike haritası, 1945 yılında yayınlanmıştır. 1945'ten itibaren, meydana gelen depremler ve deprem sismolojisindeki gelişmelere paralel olarak deprem tehlike haritası birçok kez güncellenmiştir [6]. 1996 yılında yürürlüğe giren ve uzun yıllar kullanılan deprem tehlike haritası ise olasılık yaklaşımı kullanılarak, 50 yılda aşılma olasılığ $\% 10$ olan maksimum yer ivmeleri (Peak Ground Acceleration) esas alınarak oluşturulmuştur. Bu haritada deprem riski, deprem bölgeleri yaklaşımı esas alınarak tanımlanmıştır. Harita 2018 yılında değiştirilerek coğrafi koordinatlara dayanan kontur içeren deprem tehlike haritası yayınlanmıştır. Yeni deprem tehlike haritasında ise deprem riski, spektral ivme $\left(\mathrm{S}_{\mathrm{a}}\right)$ ve spektral hız $\left(\mathrm{S}_{\mathrm{v}}\right)$ cinsinden verilmektedir. Bu çalışmalar hakkında özet bilgi içeren ve ilgili çalışmaların tümüne atıf yapan Akkar vd. [2] konu ile ilgili ayrıntılı bilgi edinmek için incelenebilir.

Son gelişmelere paralel olarak ülke genelinde TDY-2007 ve TDY-2019'dan elde edilen tasarım değerlerini inceleyen çalışmalar hızla devam etmektedir. Keskin ve Bozdoğan [8], Kırklareli Merkez bölgesinden aldıkları bir koordinat için tasarım ivme spektrumları elde etmişlerdir. Daha sonra tipik bir bina üzerinde doğrusal elastik analizler yaparak taban kesme kuvveti ve çatı deplasmanı gibi değerleri karşılaştırmışlardır. Çalışmadan elde edilen sonuç, doğal titreşim periyodu 0.5-0.6s arasında olan binanın, TDY-2019'a göre TDY-2007'den daha yüksek deprem talepleri ile zorlandığıdır. Öztürk [9] ise Türkiye'nin İç Anadolu Bölgesindeki bazı şehir merkezlerinden seçtiği koordinatları kullanarak nispeten düşük depremsellik içeren bölgelerdeki elastik ve azaltılmış spektral ivme değerlerini karşılaştırmıştır. Başaran [10] ise Afyon Kocatepe'den seçtiği 59 koordinat için 5 ve 10 katlı iki adet tipik çerçeveye gelen eşdeğer deprem kuvvetlerini TDY-2007 ve TDY-2019'a göre hesaplamıştır. Çalışma sonuçlarına göre incelenen bölge için 5 ve 10 katlı çerçevelere gelen eşdeğer deprem yükleri TDY-2019'la birlikte azalma göstermiştir. Benzer çalışmalar Ege Bölgesi [11] ile Kocaeli, Kayseri, Eskişehir ve Konya illeri içinde yapılmıştır [12]. Akkar vd. [2] tarafından sunulan çalışmada ise TDY-2019'a göre elde edilen spektrumlar ve TDY-2017'den elde edilen spektrumlar karşılaştırmalı olarak PGA ve $S_{a e}$ (elastik spektral ivme) değerleri için Türkiye genelinde sunulmuştur. Çalışmada PGA değerleri için karşılaştırma, 50 yılda aşılma olasılığı \%10 olan deprem seviyesi dikkate alınarak yapılmıştır. Sae değerleri cinsinden karşılaştırmada ise sonuçlar $\mathrm{T}=0-0.2-1.0$ ve $2.0 \mathrm{~s}$ değerleri için 50 yılda aşılma olasılığı $\% 10$ olan deprem seviyesine göre belirlenmiştir. Diğer performans seviyeleri için bilgi ise doğrudan verilmemiş, 50 y1lda aşılma olasılığ $\% 10$ olan deprem seviyesine oranlanarak kontur cinsinden verilmiştir. Çalışmadan elde edilen sonuçlara göre TDY-2019'a göre hesaplanan $\mathrm{S}_{\mathrm{ae}}$ değerleri kısa periyotlar için yüksek değerler alırken, uzayan periyotlar için ise azalmaktadır. 
Deprem bölgeleri haritasından kontur içeren deprem tehlike haritasına geçişin çok yeni olmasına bağlı olarak konu üzerinde yapılmış çalışma sayısı oldukça kısıtlıdır. Buna bağlı olarak bu çalışma kapsamında diğer çalışmalarda yapılanlara katkı sunacak şekilde Türkiye'nin en yüksek depremselliğe sahip bölgelerinden biri olan Elazı̆̆ İli ve çevresi çalışma alanı olarak seçilerek, literatürde daha önce kullanılmamış sayıda (bölge üzerinde toplam 216 adet) koordinat taranmıştır. Yapılara gelen deprem talep yüklerinin belirlenmesinde kullanılan tasarım ivme spektrumu, TDY-2007 ile TDY-2019 esas alınarak incelenmiştir. Böylelikle, tasarım yüklerinde deprem bölgesi haritası ile kontur içeren deprem tehlike haritası yaklaşımının farkları ortaya çıkarılmıştır. Elde edilen tasarım ivme spektrumları karşılaştırılarak Elazı̆̆ İli ve çevresi özelinde deprem talebinin değişimi TDY-2007'de 4 zemin sınıfı olduğundan 4 farklı zemin sınıfı ve 3 farklı performans seviyesi için elde edilmiştir. Bu yönüyle mevcut yapıların durumu hakkında bir ön bilgi sunulması amaçlanmıştır. Buna ek olarak azaltılmış tasarım ivme spektrumlarının ilgili yönetmeliklere göre değişimi de araştırılmıştır. Yeni binaların tasarımında kullanılan azaltılmış tasarım ivme spektrumları farklı bina ve taşıyıcı sistem türleri için incelenerek yüksek depremsellik barındıran bölgelerde TDY-2019'a geçişle birlikte ortaya çıkabilecek değişiklikler hakkında bir ön bilgi sunulmuştur.

\section{TDY-2007 ve TDY-2019 Tasarım İvme Spektrumları}

TDY-2007'de tasarım ivme spektrumlarının belirlenmesinde, riskin bölgesel olarak gösterildiği ve 1996 yılında yürürlüğe giren deprem tehlike haritası kullanılmıştır. Bu haritada deprem bölgeleri, olasılık yöntem kullanılarak, 50 yılda aşılma olasılığ $\% 10$ ve dönüş periyodu 475 yıl olan PGA esas alınarak belirlenmiştir [6]. Haritada Türkiye deprem riski açısından beș bölgeye ayrılmıştır.

TDY-2007'de tasarım ivme spektrumunun hesabında, spektrumunun ordinatı olan elastik spektral ivme, $\mathrm{S}_{\mathrm{ae}}(\mathrm{T})$; spektral ivme katsayısı, $\mathrm{A}(\mathrm{T})$, ile yer çekimi ivmesinin, g, çarpımıyla elde edilmektedir [4]. A(T) ise etkin yer ivme katsayısı, $A_{0}$, bina önem katsayısı, I, ve spektrum katsayısının $S(T)$ bir fonksiyonudur (Şekil 1). $A_{0}$, deprem ivmesinin büyüklüğünü gösteren bir katsayı olup deprem bölgeleri için Tablo 1'de verilmiştir. S(T) ise bina doğal titreşim periyodu $\mathrm{T}$ ile Tablo 1'de verilen yerel zemin koşullarına bağlı spektrum karakteristik periyotları $\left(\mathrm{T}_{\mathrm{A}}, \mathrm{T}_{\mathrm{B}}\right)$ kullanılarak, Şekil 1'de verilen bağıntılar yardımıyla hesaplanmaktadır.

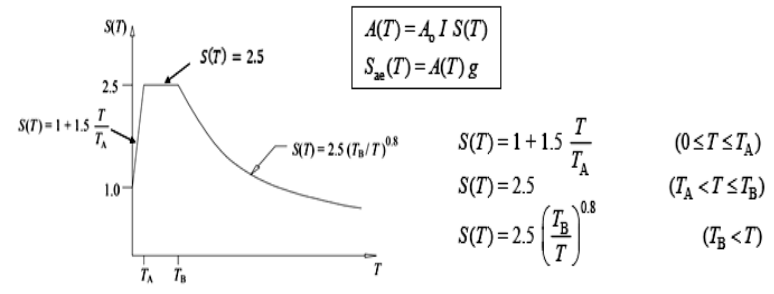

Şekil 1. TDY 2007 için tasarım ivme spektrumu.

Tablo 1. Etkin yer ivmesi katsayısı $A_{0}$ ve spektrum karakteristik periyotları $T_{A}$ ve $T_{B}$ 'nin değişimi [4].

\begin{tabular}{ccccc}
\hline Deprem bölgesi & $\mathrm{A}_{0}$ & Zemin sınıfi & $\mathrm{T}_{\mathrm{A}}$ & $\mathrm{T}_{\mathrm{B}}$ \\
\hline 1 & 0.4 & $\mathrm{Z} 1$ & 0.10 & 0.30 \\
\hline 2 & 0.3 & $\mathrm{Z} 2$ & 0.15 & 0.40 \\
\hline 3 & 0.2 & $\mathrm{Z} 3$ & 0.15 & 0.60 \\
\hline 4 & 0.1 & $\mathrm{Z} 4$ & 0.20 & 0.90 \\
\hline
\end{tabular}

Taşıyıcı sistemin doğrusal elastik olmayan davranışını dikkate almak için TDY-2007'de, spektral ivme katsayısı esas alınarak bulunan elastik deprem yükü, deprem yükü azaltma katsayısına, $\mathrm{R}_{\mathrm{a}}(\mathrm{T})$, bölünerek azaltılmaktadır. $\mathrm{R}_{\mathrm{a}}(\mathrm{T})$ ise taşıyıcı sistem davranış katsayısı R'ye ve T’ye bağlı olarak Denklem 1 yardımıyla belirlenmektedir.

$$
\begin{array}{ll}
R_{a}(T)=1.5+(R-1.5) \frac{T}{T_{A}} & 0 \leq T \leq T_{A} \\
R_{a}(T)=R & T_{A}<T
\end{array}
$$


TDY-2019'da binaya gelen deprem yüklerinin belirlenmesinde etkili olan deprem tehlike haritası ve tasarım ivme spektrumu eğrisinin tasarımında önemli değişiklikler yapılmıştır. 2019 yılında yürürlüğe giren deprem tehlike haritası bölgesel bir harita olmayıp coğrafi koordinat esaslı bir kontur haritası özelliği taşımaktadır. Şekil 2a'da gösterilen haritada deprem riski spektral ivme $\left(S_{a}\right)$ cinsinden verilmektedir. Koordinat bazlı spektral ivmeler, $\mathrm{T}=0.2 \mathrm{~s}$ ve $\mathrm{T}=1.0 \mathrm{~s}$ periyotları için zemin sınıfları ve farklı performans düzeylerini gösteren deprem yer hareket düzeyleri için olasılık deprem tehlikesi analiz yöntemi kullanılarak üretilmiştir.

Tasarım ivme spektrumunun hesabında kullanılacak harita spektral ivme katsayıları $\mathrm{S}_{\mathrm{s}}$ ve $\mathrm{S}_{1}, \mathrm{~T}=0.2 \mathrm{~s}$ ve $\mathrm{T}=1.0 \mathrm{~s}$ periyotlarda, referans zemin koşulları ve dikkate alınan deprem düzeyi için ilgili deprem tehlike haritasından elde edilmektedir [5]. Harita spektral ivme katsayıları $S_{S}$ ve $S_{1}$, zemin koşullarını gösteren zemin etki katsayıları $F_{\mathrm{S}}$ ve $F_{1}$ ile çarpılarak tasarım spektral ivme katsayıları $S_{D S}$ ve $S_{D 1}$ hesaplanmaktadır (Şekil 2b). Neticede tasarım ivme spektrumu Şekil 3b'deki gibi elde edilmektedir. Spektrumun sabit ivme bölgelerinin sınırlarını gösteren köşe periyotları $T_{A}$ ve $T_{B}$ ise ilgili koordinatın tasarım spektral ivme katsayıları $S_{D S}$ ve $S_{D 1}$ değerleri kullanarak Şekil 2b'de gösterilen şekilde hesaplanmaktadır. Ayrıca TDY-2019'da önceki yönetmelikte dört olan zemin sınıfı sayısı değiştirilerek altı adet zemin sınıfı belirlenmiştir [5]. TDY-2019 için zemin sınıfları Tablo 2'de sıralanmıştır.

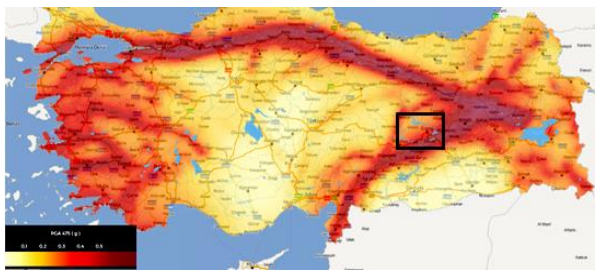

(a)
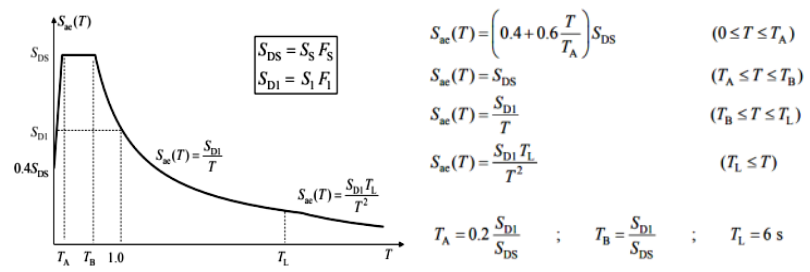

(b)

Şekil 2. (a)TDY-2019'da kullanılan Türkiye deprem tehlike haritası [13] ve Elazı̆̆’’ın konumu, (b) TDY-2019 için tasarım ivme spektrumu.

Tablo 2. TDY-2019 zemin sinıfları

\begin{tabular}{cl}
\hline Yerel Zemin Sınıfı & Zemin cinsi \\
\hline ZA & Sağlam, sert kayalar \\
\hline ZB & Az ayrışmış, orta sağlam kayalar \\
\hline ZC & Çok sıkı kum, çakıl ve sert kil tabakaları veya ayrışmış, çok çatlaklı zayıf kayalar \\
\hline ZD & Orta sıkı - sıkı kum, çakıl veya çok katı kil tabakaları \\
\hline ZE & Gevşek kum, çakıl veya yumuşak - katı kil tabakalar \\
\hline ZF & Sahaya özel araştırma ve değerlendirme gerektiren zeminler \\
\hline
\end{tabular}

TDY-2019'da doğrusal elastik deprem yüklerinin azaltılmasında esas alınacak $R_{a}(T)$, $T_{B}$ spektrum köşe periyodu sınır değer alınarak, dayanım fazlalığı katsayısı D, bina önem katsayısı, I, ve taşıyıcı sistem davranış katsayısı, R'ye bağlı olarak Denklem 2 yardımıyla hesaplanmaktadır.

$R_{a}(T)=D+\left(\frac{R}{I}-D\right) \frac{T}{T_{B}}$ $T \leq T_{B}$

$R_{a}(T)=\frac{R}{I}$

$T>T_{B}$

Her iki yönetmelikteki binaya gelen deprem yüklerinin belirlenmesinde kullanılan tasarım esasları karşılaştırıldığında aşağıda özetlenen temel farklılıklar görülmektedir.

- $\quad$ TDY-2007'de bölgesel olan deprem risk haritasının yerini TDY-2019'da coğrafi koordinat esaslı kontur içeren deprem risk haritası almıştır.

- Eski haritada deprem riski PGA cinsinden ifade edilirken, yeni haritada spektral değerler cinsinden verilmektedir.

- Yeni haritada ivme spektrumu, taşıyıcı sistemlerin performans hedefleri için 50 yılda aşılma olasılıkları sırasıyla $\% 2, \% 10, \% 50$ ve $\% 68$ olan dört adet deprem yer hareketi düzeyi için belirlenmiştir.

- TDY-2019'da spektrum köşe periyotları $\mathrm{T}_{\mathrm{A}}$ ve $\mathrm{T}_{\mathrm{B}}$ 'nin belirlenmesinde yerel zemin etkisinin yanı sıra harita spektral ivme katsayıları $\mathrm{S}_{\mathrm{SD}} \mathrm{veS}_{\mathrm{D} 1}$ 'de dikkate alınmaktadır. 
- TDY-2019'da elastik spektral ivmenin, $\mathrm{S}_{\mathrm{ae}}(\mathrm{T})$, grafiksel değişimi verilirken, TDY-2007'de spektrum katsayısının, S(T), grafiksel değişimi verilmektedir. TDY-2007'de elastik spektral ivme; spektrum katsayısının, etkin yer ivme katsayısı ve bina önem katsayısı ile artırılmasından elde edilmektedir.

- TDY-2007'de dört adet olan yerel zemin sınıfı sayısı, TDY-2019'da artırılarak altıya çıkarılmıştır. Bu çalışmada karşılaştırabilme yapabilmek amacıyla zemin sınıfları TDY-2007 ve TDY-2019 yönetmelikler arasında Tablo 3 'te verilen şekliyle eşleştirilmiştir.

- Deprem yükü azaltma katsayısında sınır değer olarak TDY-2019'da $T_{B}$ köşe periyodu dikkate alınırken TDY-2007'de ise $T_{A}$ köşe periyodu dikkate alınmaktadır. Ayrıca TDY-2019'da deprem yükü azaltma katsayısının hesabında, kısa periyotlar için taşıyıcı sistem tipine göre değişen dayanım fazlalı̆̆ı katsayısı ve bina önem katsayısı dikkate alınmaktadır. Ancak TDY-2007'de dayanım fazlalığı katsayısı sabit olarak 1.5 alınırken bina önem katsayısı ise spektral ivme katsayısının hesabında dikkate alınmaktadır

Tablo 3.TDY-2007 ve TDY-2019 zemin sınıflarının eşleştirilmesi

\begin{tabular}{ccc}
\hline TDY-2007 & TDY-2019 & Çalışmada \\
\hline Z1 & ZA & ZA \\
\hline Z2 & ZB & ZB \\
\hline Z3 & ZC & ZC \\
\hline Z4 & ZD & ZD \\
\hline
\end{tabular}

\section{3. Çalışmanın Yapıldığı Bölgenin Depremselliği}

TDY-2007 ve TDY-2019 tasarım ivme spektrumlarının karşılaş̧ırıldığı bu çalışmada, çalışma alanı olarak seçilen Elazığ İli, yıkıcı depremler üreten Doğu Anadolu Fay Zonu (DAFZ) üzerinde bulunmaktadır $[14,15]$. Şekil 2a'da deprem risk haritasında konumu gösterilen Elazı ğ İli ve çevresinde aletsel dönemde meydana gelen ve Tablo 4'de sıralanan hasar yapıcı depremler bölgenin aktifliğini göstermesi bakımından önemlidir. $\mathrm{Bu}$ nedenle çalışma kapsamında dikkate alınan bölge Türkiye'nin özellikle Doğu Anadolu Bölgesi'nin deprem riskinin değişimini temsil etmektedir.

Tablo 4. Elazığ İli ve çevresinde meydana gelen hasar yapıcı depremler [16, 17, 18, 19, 20].

\begin{tabular}{lllc|llll}
\hline No & Tarih & Yer & Büyüklük & No & Tarih & Yer & Büyüklük \\
\hline 1 & 29.05 .1789 & Elazı̆ & 7.0 & 19 & 22.05 .1971 & Bingöl & $6.8(7.1)$ \\
\hline 2 & 12.05 .1866 & Bingöl-Karlıva & 7.2 & 20 & 06.09 .1975 & Lice & 6.6 \\
\hline 3 & 1866 & Hazar Gölü Güneyi & 5.5 & 21 & 1976 & Çaldıran Muradiye & 7.5 \\
\hline 4 & 03.05 .1874 & Palu-Hazar Gölü & 7.1 & 22 & 25.03 .1977 & Elazığ-Palu & 5.1 \\
\hline 5 & 1874 & Maden-Diyarbakır & 6.1 & 23 & 1983 & Erzurum Kars & 7.1 \\
\hline 6 & 27.03 .1875 & Keban-Hazar-Sincik & 6.7 & 24 & 05.05 .1986 & Doğanşehir & 5.9 \\
\hline 7 & 1875 & Karlıva-Palu & 6.1 & 25 & 06.06 .1986 & Doğanşehir & 5.6 \\
\hline 8 & 1889 & Palu & 4.3 & 26 & 13.03 .1992 & Erzincan & 6.8 \\
\hline 9 & 1893 & Malatya & & 27 & 15.03 .1992 & Pülümür & 5.8 \\
\hline 10 & 02.03 .1905 & Hazar Gölü-Sincik & 6.8 & 28 & 05.12 .1995 & Kiğ1 & 5.7 \\
\hline 11 & 15.12 .1934 & Bingöl Çapakçur & 5.8 & 29 & 13.04 .1998 & Karlıva & 5.0 \\
\hline 12 & 17.08 .1949 & Karlıva & 6.7 & 30 & 27.01 .2003 & Tunceli-Pülümür & 6.2 \\
\hline 13 & 04.02 .1950 & Bingöl Kığ1 & 5.5 & 31 & 01.05 .2003 & Bingöl & 6.4 \\
\hline 14 & 07.07 .1957 & Bingöl Kığı Büyüksu & 5.1 & 32 & 14.08 .2004 & Elazı̆̆ & 5.7 \\
\hline 15 & 14.06 .1964 & Malatya & 6.0 & 33 & 23.03 .2005 & Bingöl & 5.7 \\
\hline 16 & 19.08 .1966 & Varto & 6.9 & 34 & 21.02 .2007 & Elazı̆̆-Sivrice & 5.9 \\
\hline 17 & 26.07 .1967 & Pülümür & 5.9 & 35 & 08.03 .2010 & Elazığ-Kovancılar & $5.8-5.6$ \\
\hline 18 & 24.09 .1968 & Kı̆̆1 Karakoçan & 5.1 & 36 & 24.01 .2020 & Elazı̆̆-Sivrice & 6.5 \\
\hline
\end{tabular}

Çalışma Elazığ İli ve çevresini içine alacak şekilde $18020 \mathrm{~km}^{2}$ dikdörtgen alan dikkate alınarak planlanmış olup bu alan Türkiye'nin yaklaşık \%2.3'üne karşı gelmektedir. Çalışma alanı Şekil 3'de gösterildiği gibi yatay ve düşeyde $10 \mathrm{~km}$ genişliğinde aralıklara bölünmüştür. 


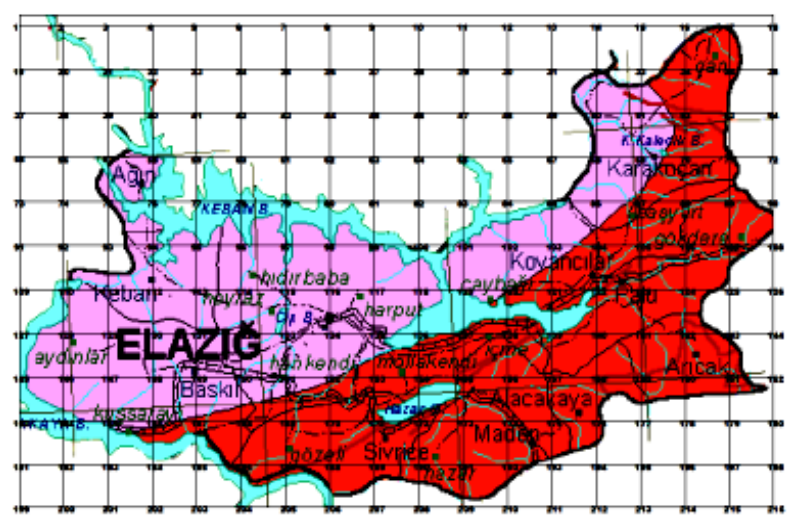

Şekil 3. Çalışma alanı üzerinde eski ve yeni spektrumları karşılaştırmak için seçilen noktalar

\section{Hesaplanan Tasarım İvme Spektrumları}

Çalışma kapsamında öncelikle mevcut yapılara gelen deprem yüklerindeki değişimin ortaya çıkartılabilmesi amacı ile tasarım ivme spektrumları azaltılmadan karşılaştırılmıştır. Çalışma bölgesindeki 216 noktanın koordinatları esas alınarak yeni deprem tehlike haritasına göre tasarım ivme spektrumları, 3 adet performans seviyesi (aşılma olasılı̆̆ 50 yılda \%50, \%10 ve \%2) ve 4 farklı zemin tipi (ZA, ZB, ZC ve ZD) için elde edilmiştir. Çalı̧̧mada TDY-2019'a göre toplam 4 zemin x 3 deprem seviyesi x 216 nokta $=2592$ adet tasarım ivme spektrumu hesaplanmıştır. Eski deprem tehlike haritasına göre Elazığ İli ve çevresi risk açısından birinci ve ikinci derece deprem bölgelerinde bulunmaktadır. Eski deprem tehlike haritası ve TDY-2007 tasarım bağıntıları kullanılarak, 4 farklı zemin tipi için aşılma olasılığı 50 yılda \%10 olan tasarım ivme spektrumu 216 nokta için elde edilmiştir. Daha sonra bu tasarım ivme spektrumları 1.5 ile çarpılarak aşılma olasıllğı 50 yılda $\% 2$ olan tasarım ivme spektrumları ve 0.5 ile çarpılarak aşılma olasılığı 50 yılda $\% 50$ olan tasarım ivme spektrumları elde edilmiştir. Her iki harita kullanılarak elde edilen tasarım ivme spektrumları 0'dan 6s periyot aralığına kadar $0.01 \mathrm{~s}$ artışlarla hesaplanmıştır.

\section{Tasarım İvme Spektrumlarının Karşılaştırılması}

Çalışma alanında dikkate alınan 216 nokta için TDY-2019 esas alınarak elde edilen tasarım spektral ivme talepleri TDY-2007'den elde edilenlere oranlanarak grafiksel olarak verilmiştir (Şekil 4). Karşlaştırma her bir performans seviyesi ( $H K$, hemen kullanım; $C G$, can güvenliği ve $G \ddot{O}$, göçme öncesi) ve Tablo 3 'te verilen zemin sınıfları için yapılmıştır.

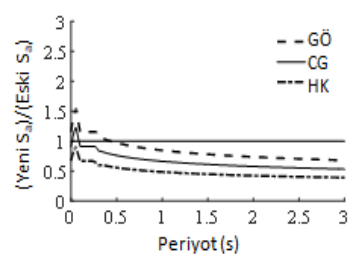

(a)

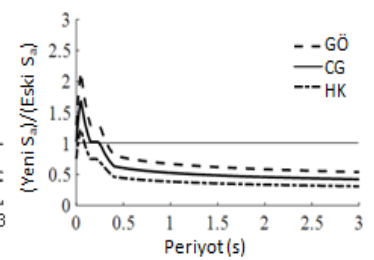

(b)

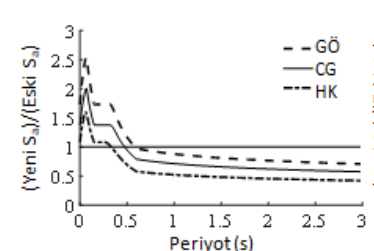

(c)

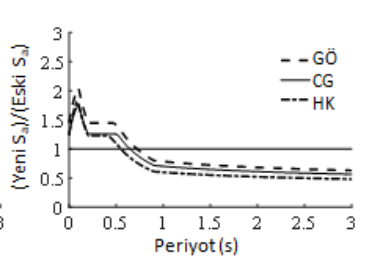

(d)

Şekil 4. Yeni tasarım ivme spektrumunun eskiye oranı; zemin sınıfları (a) ZA, (b) ZB, (c) ZC, (d) ZD

TDY-2019 tasarım ivme spektrumunun TDY-2007 tasarım ivme spektrumuna oranla sadece kısa periyotlarda (çoğunlukla $0.75 \mathrm{~s}$ 'den küçük periyotlarda) daha büyük değerler verdiği görülmektedir. Uzun periyotlarda ise çalışmada dikkate alınan tüm zemin tipleri ve performans seviyeleri için TDY-2019 tasarım ivme spektrumu daha küçük değerler vermektedir. Bu sonuçlar, doğal titreşim periyodu yaklaşık $0.75 \mathrm{~s}$ 'den büyük olan yapıların, TDY-2007 tasarım ivme spektrumuna göre TDY-2019'da daha düşük deprem yükü talepleri ile karşılaşılacağını göstermektedir. Şekil 4'ten elde edilen bir diğer sonuç ise her iki deprem yönetmeliğinin tasarım ivme spektrumları arasındaki en belirgin farkların, ZC zemin sınıfında ve GÖ performans 
seviyesinde ortaya çıkmasıdır. ZA tipi zeminler üzerinde konumlanmış yapılarda CG ve GÖ performans seviyeleri için tasarım ivme değerlerinin 1-1.5 arasında artış gösterdiği görülmektedir. Ancak 1.5 kata varan bu artış sadece 0.1s civarındaki periyot bölgesinde oluşmaktadır. Daha büyük periyot değerleri için ise en büyük artış değerinin 1.2 civarında kaldığı görülmektedir. Benzer sonuçlar ZB tipi zeminler üzerinde inşa edilen yapılar içinde geçerlidir. ZC ve ZD tipi zeminler üzerindeki yapılar için ise çok küçük periyot değerlerine denk gelen artış miktarlarını göz ardı edersek, ivme değerlerindeki artışın sırasıyla 1.7 ve 1.3 kat ile sınırlı kaldığı görülmektedir. ZA, ZB ve ZC tipi zeminlerde, gözlenen artışlar yaklaşık 0.5 s periyot bölgesine kadar sürerken, ZD tipi zeminlerde ise gözlenen artışın yaklaşık 0.75 s civarına kadar sürdüğü görülmektedir.

Bu sonuçlar değerlendirilirken Şekil 4’ün çalışmada dikkate alınan tüm koordinatların ortalama değerleri kullanılarak çizildiğini göz önünde bulundurmak gerekir. $\mathrm{Bu}$ nedenle sonuçlarda standart sapmaların ortalamalara oranları yüksektir. Standart sapma oranını düşürebilmek için, eski deprem tehlike haritasına göre birinci ve ikinci derece deprem bölgelerinde yer alan koordinatlar için ayrı ayrı spektrum karşılaştırmaları yapılarak, sırasıyla Şekil 5 ve Şekil 6'da gösterilmiştir.

Şekil 5'den TDY-2019 tasarım ivme spektrumunun TDY-2007 tasarım ivme spektrumuna göre maksimum $0.5 \mathrm{~s}$ ve daha küçük periyotlar için daha büyük değerler verdiği görülmektedir. Ancak Şekil 6'da TDY-2019 tasarım spektrumu $0.75 \mathrm{~s}$ periyoda kadar daha yüksek değerler vermektedir. Bu sonuç, eski deprem tehlike haritasına göre ikinci derece deprem bölgesinde bulunan alanlardaki yapıların, D tipi zemin sınıfı üzerinde bulunması halinde daha uzun periyot aralığında daha fazla deprem talebi ile zorlanacağını göstermektedir.

Tasarım ivme spektrumlarının karşılaştırılmasından elde edilen sonuçlar genel olarak kısa periyot bölgesinde kalan binaların ( $\mathrm{T}<0.75 \mathrm{~s})$ TDY-2019'un şartları açısından yeniden değerlendirilmesi gerektiğini göstermektedir. Bu periyot aralığında genelde az katlı binaların olduğu bilinmektedir. Şekil 4-6'da verilen grafikler incelendiği zaman elastik deprem yüklerinin çok kısa periyotlarda $(\mathrm{T}<0.2)$ sert zeminlerde 2 kata kadar, yumuşak zeminlerde ise 2.5 kata kadar arttığı görülmektedir. Daha uzun periyot bölgelerinde $(0.2<\mathrm{T}<0.75)$ ise bu artış genelde 1-1.5 kat aralığında değişmektedir. Bu periyot bölgesinin dışında ise TDY-2019'dan elde edilen değerlerin TDY-2007'ye kıyasla daha düşük kaldığg görülmektedir.

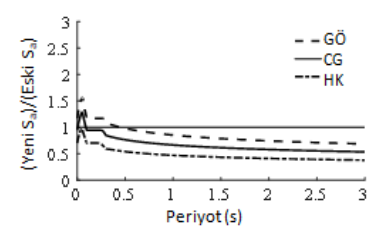

(a)

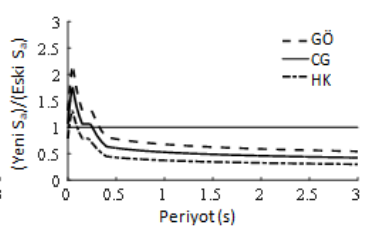

(b)

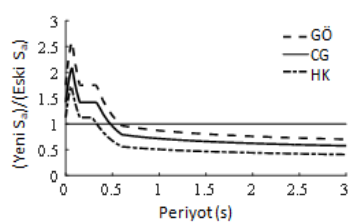

(c)

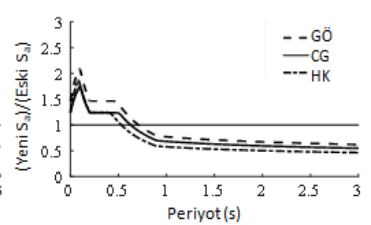

(d)

Şekil 6. Birinci bölge için yeni tasarım ivme spektrumunun eskiye oranı; zemin sınıfları (a) ZA, (b)ZB, (c) ZC, (d) ZD

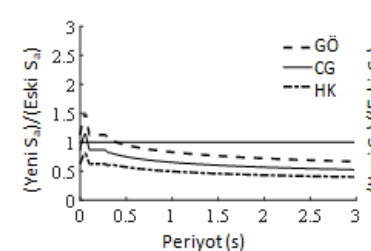

(a)

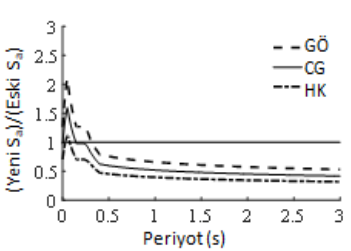

(b)

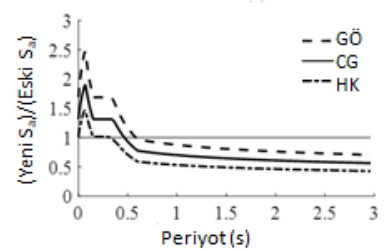

(c)

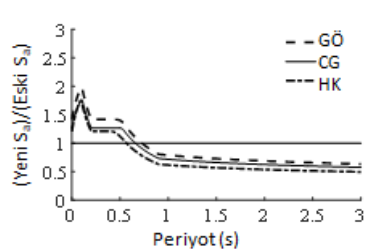

(d)

Şekil 6. İkinci bölge için yeni tasarım ivme spektrumunun eskiye oranı; zemin sınıfları (a) ZA, (b)ZB, (c) ZC, (d) ZD

\section{Azaltılmış Tasarım İvme Spektrumlarının Hesaplanması}

Yeni yapılacak binaların tasarımında kullanılacak azaltılmış tasarım ivme spektrumlarının karşılaştırılması yoluyla, tasarım yüklerinin TDY-2019'a göre değişiminin etkisi farklı tipte betonarme binaları kapsayacak şekilde incelenmiştir. Bunun için TDY-2007 ve TDY-2019 yönetmeliklerine göre tanımlanan azaltılmış tasarım ivme spektrumları, farklı tip binalar ve farklı tip betonarme taşıyıcı sistemler için karşılaştırılmıştır. Bu amaçla her bina kullanım sınıfından (BKS) seçilen bina tipleri (okul, hastane, alışveriş merkezi-AVM ve konut) için karşılaştırmalar yapılmıştır. Karşılaştırmada binaların betonarme çerçeve ve betonarme çerçeve-perde taşıyıcı sistemlerine sahip oldukları kabul edilmiştir. Tablo 5 ve 6'da TDY-2019 ve TDY-2007'de spektrumların 
azaltılmasında kullanılan katsayılara ait detaylar sırasıyla verilmiştir. Tasarım ivme spektrumların azaltılmasında TDY-2007 için Denklem 1a, 1b ve TDY-2019 için ise Denklem 2 kullanılmıştır.

Tablo 5. TDY-2019'da elastik tasarım ivme spektrumlarının azaltılmasında kullanılan katsayılar

\begin{tabular}{ccccccc}
\hline \multirow{2}{*}{ Bina Tipi } & \multicolumn{3}{c}{$\begin{array}{c}\text { Taşıc1 Sistem } \\
\text { Çerçeve }\end{array}$} & \multicolumn{3}{c}{ Taşıc1 Sistem } \\
& $\mathrm{R}$ & $\mathrm{D}$ & $\mathrm{I}$ & $\mathrm{R}$ & $\mathrm{D}$ & $\mathrm{I}$ \\
\cline { 2 - 6 } & $\mathrm{R}$ & 3 & 1.5 & 7 & 2.5 & 1.5 \\
\hline Okul & 8 & 3 & 1.5 & 7 & 2.5 & 1.5 \\
\hline Hastane & 8 & 3 & 1.2 & 7 & 2.5 & 1.2 \\
\hline Konut & 8 & 3 & 1.0 & 7 & 2.5 & 1.0 \\
\hline AVM & 8 & 3
\end{tabular}

Çalışma kapsamındaki her bir koordinat için (216 koordinat); (i) 4 bina tipi, (ii) 2 taşıyıcı sistem tipi, (iii) 3 performans seviyesi, (iv) 4 zemin tipine göre TDY-2019 için toplam $216 \times 4 \times 2 \times 3 \times 4=20736$ adet azaltılmış ivme spektrumu hesaplanmıştır. Bu ivme spektrumları TDY-2007'ye göre hesaplanan spektrumlar ile oranlanmıştır. Elde edilen sonuçların ortalaması alınarak azaltılmış tasarım ivme spektrum oranları elde edilmiştir.

Tablo 6. TDY-2007'de elastik ivme spektrumlarının azaltılmasında kullanılan katsayılar

\begin{tabular}{ccccccc}
\hline \multirow{2}{*}{ Bina Tipi } & \multicolumn{3}{c}{ Çerçeve } & \multicolumn{3}{c}{ Çerçeve + Boşluksuz Perde } \\
\cline { 2 - 6 } & $\mathrm{R}$ & $\mathrm{D}$ & $\mathrm{I}$ & $\mathrm{R}$ & $\mathrm{D}$ & $\mathrm{I}$ \\
\hline Okul & 8 & 1.5 & 1.4 & 7 & 1.5 & 1.4 \\
\hline Hastane & 8 & 1.5 & 1.5 & 7 & 1.5 & 1.5 \\
\hline Konut & 8 & 1.5 & 1.2 & 7 & 1.5 & 1.2 \\
\hline AVM & 8 & 1.5 & 1.0 & 7 & 1.5 & 1.0 \\
\hline
\end{tabular}

\section{Azaltılmış Tasarım İvme Spektrumlarının Karşılaştırılması}

Sonuçlar çalışmada dikkate alınan zemin sınıfları ve performans seviyeleri dikkate alınarak düzenlenmiştir. Okul tipi binalarda azaltılmış tasarım ivme spektrumları için karşılaştırma eski deprem tehlike haritasındaki bölgeler için ayrı ayrı hesaplanmıştır. Deprem bölgeleri dikkate alınarak yapılan karşılaştırmaya ait grafikler sayfa sayısı ile ilgili kısıtlamalar sebebiyle sunulamamıştır. Ancak farklılık gözlenen durumlar metin içinde belirtilmiştir. Deprem bölgeleri dikkate alınarak yapılan karşıllaştırmanın bina tipinden bağımsız olarak genelleştirilebileceği düşünülerek, anlaşılabilirlik adına diğer bina tipleri için bölge ayrımı yapılmadan tüm koordinatlar dikkate alınarak karşılaştırılma yapılmıştır.

TDY-2019'dan elde edilen azaltılmış tasarım ivme spektrumunun TDY-2007 azaltılmış tasarım ivme spektrumuna göre değişimi, BKS=1'de yer alan okul türü binalarda taşıyıcı sistemin çerçeve olması durumu için Şekil 7'de verilmiştir. Taşıyıcı sistemin perde-çerçeve olması durumunda elde edilen sonuçların çerçeve taşıyıcı sistem için elde edilen sonuçlara çok benzer olduğu görüldüğünden sayfa sayısı limitine bağlı olarak sonuçlar burada ayrıca sunulmamıştır.
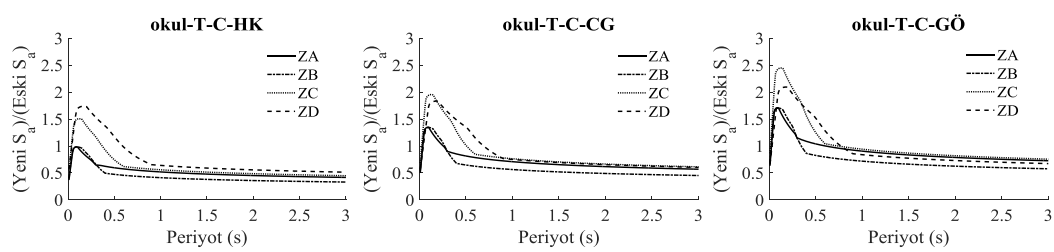

Şekil 7. Çerçeve taşıyıcı sisteme sahip okul binaları için azaltılmış tasarım ivme spektrum oranının değişimi

Okul tipi binaların azaltılmış tasarım ivme spektrumu eğrileri karşılaştırıldığında kısa periyot bölgelerinde $(\mathrm{T}<0.75 \mathrm{~s}$ ) ve özellikle zayıf zeminlerde (ZC ve ZD zemin sınıfi), TDY-2019 kullanılarak elde edilen sonuçların daha büyük olduğu görülmektedir. Aradaki fark özellikle GÖ performans seviyesinde eski deprem tehlike haritasına göre ikinci derece deprem bölgesinde bulunan koordinatlarda en büyük değeri almaktadır. Uzun periyot bölgelerinde ise ivme spektrumları arasındaki oran 0.5 ile 1 arasındadır. Güçlü zeminlerde (ZA ve ZB 
zemin sınıfi) ise zayıf zeminlere oranla daha kısa periyot $(\mathrm{T}<0.5 \mathrm{~s})$ aralığında TDY- 2019 kullanılarak elde edilen değerler daha büyüktür. Okul tipi binalarda elde edilen farklar üzerinde, TDY 2007'de 1.4 olan bina önem katsayısının, TDY 2019'da 1.5 olarak değiştirilmesi de etkilidir. Okul tipi binalarda taşıyıcı sistem seçiminin (çerçeve, perde-çerçeve) spektrum değişimi üzerindeki etkisinin ise güçlü zeminlerde belirgin olmadığı, zayıf zeminlerde ise çok küçük düzeyde olduğu anlaşılmıştır. Sonuç olarak, TDY-2019 kullanıldığında özellikle az katlı ve zayıf zeminlerde bulunan okul türü binaların 2.5 kata varan daha yüksek deprem talepleri ile zorlanacağı görülmektedir.

Hastane, AVM ve konut türü binalarda taşıyıcı sistemin çerçeve veya perde-çerçeve olması durumu için TDY-2019 kullanılarak ortaya çıkan azaltılmış tasarım ivme spektrumunun değişimi hesaplanmıştır. Çerçeve ile perde-çerçeve sistem için elde edilen sonuçlar benzer olduğu için grafiklerde sadece çerçeve sisteme ait sonuçlar sırasıyla Şekil 8 -10’de verilmiştir.
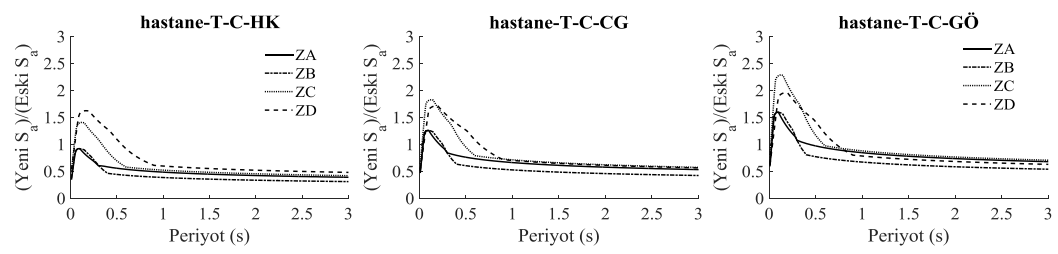

Şekil 8. Hastane tipi binalarda tüm koordinatlar için azaltılmış tasarım ivme spektrumu oranının değişimi

Hastane ve AVM tipi binalarda TDY-2019 kullanılarak elde edilen değerlerin (Şekil 10) zayıf zeminlerde HK, CG ve GÖ performans seviyelerinde, kısa periyot değerleri $(\mathrm{T}<1 \mathrm{~s})$ için sırasıyla 1.7-1.9 ve 2.4 kata varan artışlar elde edilmiştir. Güçlü zemin sınıfları için ise HK, CG ve GÖ performans seviyelerinde, daha kısa periyot değerleri $(\mathrm{T}<0.5 \mathrm{~s})$ için sırasıyla 1.0-1.4 ve 1.7 kat ile sınırlı kalmıştır.
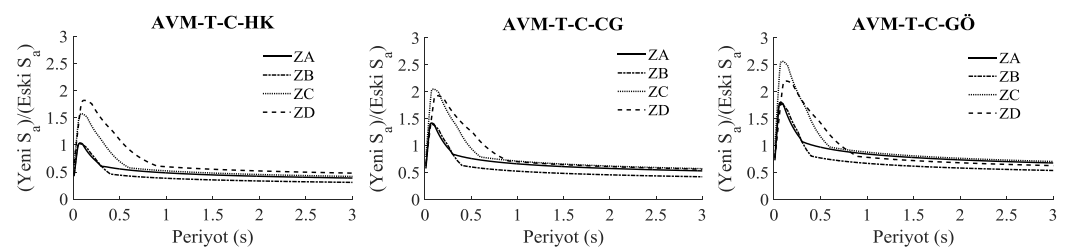

Şekil 9. Alı̧̧veriş merkezi (AVM) tipi binalarda tüm koordinatlar için azaltılmış tasarım ivme spektrum oranının değişimi

Konut tipi binalar için elde edilen sonuçlar zayıf zeminlerde HK, CG ve GÖ performans seviyelerinde, kısa periyot değerleri $(\mathrm{T}<1 \mathrm{~s})$ için sırasıyla 2.0-2.3 ve 3.0 kata varan artışlar olduğunu ortaya koymuştur (Şekil 10). Güçlü zemin sınıfları için ise HK, CG ve GÖ performans seviyelerinde bu artışlar $\mathrm{T}<0.5 \mathrm{~s}$ değerleri için sırasıyla 1.2-1.6 ve 2.0 kat ile sınırlı kalmıştır. Bu sonuçlar, TDY-2019'da en büyük deprem yükü talep artışının konut türü binalarda olduğunu göstermektedir.
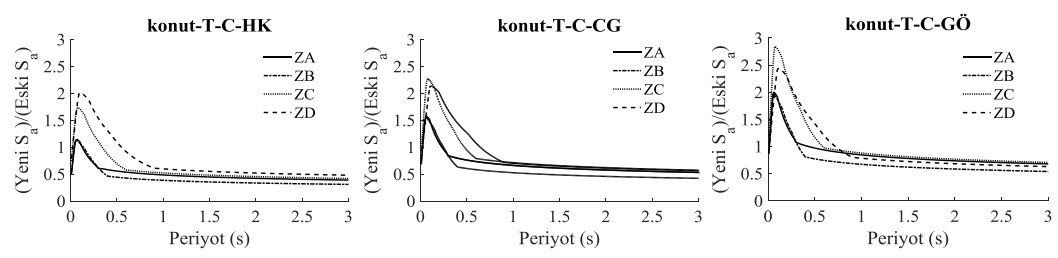

Şekil 10. Konut tipi binalarda tüm koordinatlar için azaltılmış tasarım ivme spektrum oranının değişimi

\section{Sonuçlar}

Çalışmada, TDY-2019 kullanılarak elde edilen tasarım ivme spektrumları, TDY-2007 kullanılarak elde edilen tasarım ivme spektrumları ile karşılaştırılmıştır. Karşılaştırılma zemin sınıfları ve performans seviyeleri parametreleri için yapılmıştır. Çalışmanın devamında farklı bina türleri ve taşıyıcı sistem tipleri için azaltılmış tasarım ivme spektrumları incelenerek, deprem talep değişimi için elde edilen veriler, tasarımcıyı yönlendirecek 
anlamlı sonuçlara dönüştürülmüştür. Çalışmada incelenen farklı bina türleri; (i) okul, (ii) hastane, (iii) konut ve (iv) AVM olarak seçilmiştir. Taşıyıcı sistem tipleri ise kullanım yaygınlığına bağlı olarak betonarme çerçeve ve çerçeve-perde olarak belirlenmiştir. Sayısal çalışmadan elde edilen veriler incelendiğinde aşağıda sıralanan sonuçlara ulaşılmıştır.

- Kısa periyot bölgelerinde TDY-2019'da TDY-2007'ye oranla 2.5 kata varan talep artışları gözlenmiştir. Uzun periyot bölgelerinde ise TDY-2019'dan elde edilen deprem talebi azalarak TDY-2007'den elde edilen deprem talebinin yaklaşık yarısı kadar olmuştur.

- TDY-2019'dan elde edilen deprem talep artışları en yüksek değerine zayıf zeminlerde ve GÖ performans seviyesinde ulaşmıştır. Özellikle ZC tipi zeminlerde incelenen bütün durumlar için en büyük talep artışı elde edilmiştir. Artışların yaygın olduğu periyot aralığı ise ZD tipi zeminlerde daha geniş olarak gözlenmiştir.

- Okul tipi binalarda, kısa periyot bölgelerinde özellikle zayıf zeminlerde deprem taleplerinde artış gözlenmiştir. Ülkemizde çoğunlukla az katlı tasarlanan okul tipi binaların talep artışı gözlenen periyot aralığında olması yüksek olasılıklı bir durumdur. Bu nedenle okul tipi binaların talep artışları dikkate alınarak ayrıntılı sayısal çalışmalarla incelenmesinin uygun olacağı düşünülmektedir.

- Hastane ve AVM tipi binalarda da okul tipi binalar gibi kısa periyot bölgelerinde talep artışı gözlenmiştir.

- Konut tipi binalarda ise diğer bina tiplerine oranla en yüksek deprem talep artışları gözlenmiştir.

Elde edilen sonuçlar, spektrumlara uyumlu yer hareketi kayıtları seçilerek yapılacak doğrusal olmayan zaman tanım alanında analizlerle desteklenirse, mevcut bina stokunun güncel deprem tehlikesine göre performans durumu daha ayrıntılı olarak ortaya çıkartılabilir.

\section{Kaynaklar}

[1] Kramer SL. Geotechnical Earthquake Engineering. Prentice Hall 1996, 653 pp.

[2] Akkar S, Azak T, Çan T et al. Evolution of seismic hazard maps in Turkey. Bull Earthquake Eng, 2018; 16(3197).

[3] TDY 1998. Afet bölgelerinde yapılacak yapılar hakkında yönetmelik. Bayındırlık ve İskan Bakanlığı, Ankara, 1998.

[4] TDY 2007 Deprem Bölgelerinde Yapılacak Yapılar Hakkında Yönetmelik. Bayındırlık ve İskan Bakanlığı, Ankara, 2007.

[5] TDY 2019. Türkiye Bina Deprem Yönetmeliği. Afet ve Acil Durum Yönetimi Başkanlığı, Ankara, 2018.

[6] Özmen B. Türkiye deprem bölgeleri haritalarının tarihsel gelişimi. Türkiye Jeoloji Bülteni, 2012; 55(1).

[7] Wood HO, Neumann F. Modified Mercalli intensity scale of 1931. Bulletin of the Seismological Society of America, $1931 ; 21(4), 277-283$.

[8] Keskin\&Bozdoğan. 2007 ve 2018 Deprem yönetmeliklerinin Kirklareli İli özelinde değerlendirilmesi. Kirklareli University Journal of Engineering and Science, 2018; 4(1), 74-90.

[9] Öztürk M. 2018 Türkiye bina deprem yönetmeliği ve Türkiye deprem tehlike haritası ile ilgili iç anadolu bölgesi bazında bir değerlendirme. Selçuk-Teknik Dergisi, 2018; 17(2).

[10] Başaran V. Türkiye bina deprem yönetmeliğine (TBDY2019) göre Afyonkarahisar için deprem yüklerinin değerlendirilmesi. AKÜ FEMÜBİD, 2018; 18, 1028-1035.

[11] Seyrek E. Yeni Türkiye sismik tehlike haritasının Ege Bölgesi için değerlendirilmesi. NÖHÜ Müh. Bilim. Derg., 2020; 9(1), 414-423.

[12] Koçer M., Nakipoğlu A., Öztürk B., Al-Hagrı M.G., ArslanM.H. Deprem kuvvetine esas spektral ivme değerlerinin TBDY 2018 ve TDY 2007'ye göre karşılaştırılması. Selçuk-Teknik Dergisi, 2018; 17(2), 43-58.

[13] Afet ve Acil Durum Yönetim Başkanlığı. Türkiye Deprem Tehlike Haritaları İnteraktif Web Uygulaması, https://deprem.afad.gov.tr/deprem-tehlike-haritasi, 2019.

[14] Arpat E, Şaroğlu F. Doğu Anadolu Fayı ile ilgili bazı gözlem ve düşünceler. MTA Dergisi, 1972; 78, 44-50.

[15] Palutoğlu M, Tanyolu E, Elazı̆̆ İl Merkezi Yerleşim Alanının Depremselliği. Fırat Ünv. Fen ve Müh. Bil. Dergisi, 2006; 18 (4), 535-546.

[16] 8 Mart 2010 Elazığ Kovancılar Depremi Değerlendirme Raporu. Afet ve Acil Durum Yönetim Başkanlığı, Rapor No. 025.343/6056.1, Mayıs 2010, Ankara.

[17] Kalafat D, Zülfikar C, Vuran E, Kamer Y. 08 Mart 2010 Başyurt-Karakoçan (Elazığ) depremi, Kandilli Rasathanesi ve Deprem Araştırma Enstitüsü, Mart 2010, İstanbul.

[18] Celep Z, Erken A, İlki A, Taşkın B.8 Mart 2010 Kovancılar- Elazığ Depremi ön mühendislik raporu. İTÜ Deprem Mühendisliği ve Afet Yönetimi Enstitüsü, 2010, İstanbul.

[19] Kandilli Rasathanesi ve Deprem Araştırma Enstitüsü, Büyük depremler. http://www.koeri.boun.edu.tr/sismo/2/deprembilgileri/buyuk-depremler/, 2019.

[20] 24 Ocak Sivrice-Elazığ Depremi Basın Bülteni, B.Ü. Kandilli Rasathanesi ve DAE. Bölgesel Deprem-Tsunami İzleme ve Değerlendirme Merkezi.http://www.koeri.boun.edu.tr/sismo/2/24-ocak-sivrice-elazig-depremi-2/, 2020. 